\title{
LA FIRMA ELECTRÓNICA DIGITAL EN VENEZUELA
}

\author{
Héctor R. Peñaranda Quintero \\ Universidad de Zulia, Venezuela
}

Resumen.- En la actualidad la firma manuscrita permite certificar el reconocimiento, la conformidad y/o el acuerdo de voluntades sobre un documento por las partes firmantes que forman parte de la transacción, lo que trae consecuencias legales claras y reconocimiento jurídico al instante. Ahora bien cuando nos encontramos con las transacciones que se realizan a través de las redes de información la situación varía en gran magnitud, porque en este tipo de contratos electrónicos la firma manuscrita no puede ser insertada en el documento. De esta forma es que en materia digital se ha suplantado la llamada firma manuscrita por la llamada firma digital. La firma manuscrita tiene un reconocimiento legal alto, a pesar de que pueda ser falsificada, pero la firma manuscrita tiene peculiaridades que la hacen fácil de realizar, de comprobar y vincular a quién la realiza, porque la verdadera firma manuscrita sólo puede ser realizada por una persona y puede ser comprobada por cualquiera con la ayuda de una muestra.

Palabras clave.- Firma, digital, electrónica, mensajes de datos.

\section{Firma digital}

En materia de firma digital, para intentar conseguir los mismos efectos legales que la firma manuscrita, se requiere el uso de la criptología y el empleo de algoritmos matemáticos.

Se hace necesario un entorno seguro en relación con la autenticación digital. En la práctica existen varios métodos para firmar documentos digitalmente, que van desde muy sencillo como el hecho de insertar la imagen escaneada de una firma manuscrita en un documento, lo que no permite otorgarle validez jurídica a la firma. Sin embargo, existen otros métodos muy avanzados como la firma digital que utiliza la criptografía de clave pública, que logra darle validez jurídica al documento y a la firma. El fin que persigue la firma digital es el mismo que el de la firma ológrafa, es decir, dar asentimiento y compromiso con el documento firmado, lo que trae como consecuencia positiva facilitar la autenticación a distancia entre partes que no necesariamente se conocen, proveyendo seguridad y confianza en las redes abiertas, constituyendo de esta forma la clave para el desarrollo del comercio electrónico en Internet.

El Artículo 7 de la Ley Modelo de UNCITRAL sobre Comercio Electrónico establece: "1) Cuando la ley requiera la firma de una persona, ese requisito quedará satisfecho en relación con un mensaje de datos: a) Si se utiliza un método para identificar a esa persona y para indicar que esa persona aprueba la información que figura en el mensaje de datos; y b) Si ese método es tan fiable como sea apropiado para los fines para los que se generó o comunicó el 
mensaje de datos, a la luz de todas las circunstancias del caso, incluido cualquier acuerdo pertinente".

El artículo 1 del Proyecto de Régimen Uniforme para las Firmas Electrónicas de UNCITRAL, establece que por firma electrónica se entenderá los datos en forma electrónica adjuntos a un mensaje de datos o lógicamente vinculados con él, y que se utilicen para identificar al firmante del mensaje de datos e indicar que el firmante aprueba la información contenida en el mensaje de datos.

Es importante destacar que las firmas digitales son las firmas electrónicas avanzadas definidas en el artículo 2, apartado 2 de la Directiva comunitaria y el artículo 2, apartado b) del Real Decreto Ley español sobre firma electrónica.

La Directiva comunitaria, al igual que el Decreto Ley español, regulan la firma electrónica en general, pero también la firma digital en particular, tratando de abarcar otras firmas electrónicas, que están basadas en técnicas distintas de la criptografía asimétrica, es decir, de técnicas disponibles o que están en desarrollo y que permitan cumplir con las funciones características de las firmas manuscritas en un medio electrónico.

El artículo 2 del Decreto Ley sobre Mensajes de Datos y Firmas Electrónicas de Venezuela, define la firma electrónica de la siguiente manera:

“Artículo 2. A los efectos del presente Decreto-Ley, se entenderá por:

...Firma Electrónica: Información creada o utilizada por el Signatario, asociada al Mensaje de Datos, que permite atribuirle su autoría bajo el contexto en el cual ha sido empleado...".

El artículo $3^{\circ}$ de la Ley de Firmas y Certificados Digitales de Perú (Ley No. 27269), publicada en el Diario Oficial El Peruano el día 28 de mayo de 2000, establece que la "firma digital es aquella firma electrónica que utiliza una técnica de criptografía asimétrica , basada en el uso de un par de claves único; asociadas una clave privada y una clave pública relacionadas matemáticamente entre sí, de tal forma que las personas que conocen la clave pública no puedan derivar de ella la clave privada".

Es importante mencionar que en Perú como consecuencia de la publicación de la Ley de Firmas y Certificados Digitales, se publicó la Ley № 27291 en el Diario Oficial El Peruano con fecha 24 de junio del 2000 , la cual modificó el Código Civil, permitiendo utilizar los medios electrónicos para la comunicación de la manifestación de voluntad y la utilización de la firma electrónica, sobre todo en el área de contratos.

En el marco europeo la Propuesta de la Directiva del Parlamento Europeo y del Consejo establece un marco común para la firma electrónica [COM(1998) 297 final], publicada en el DOCE el 23 de octubre de 1998. En el artículo 2, define firma electrónica como : 
"la firma en forma digital integrada en unos datos, anexa a los mismos o asociada con ellos, que utiliza un signatario para expresar conformidad con su contenido y que cumple los siguientes requisitos:

a) estar vinculada al signatario de manera única;

b) permitir la identificación del signatario ;

c) haber sido creada por medios que el signatario pueda mantener bajo su exclusivo control, y

d) estar vinculada a los datos relacionados de modo que se detecte cualquier modificación ulterior de los mismos"

La Firma digital constituye una tecnología que consiste en la utilización de un método de encriptación llamado asimétrico o de clave pública. Éste método se refiere a la creación de una clave pública y otra privada asociadas a un sujeto. La clave pública es conocida por todos los sujetos intervinientes en el sector, pero la privada, sólo conocida por el sujeto en cuestión. Esta es la forma ideada para establecer una comunicación segura, de manera que el mensaje se encripta con la clave pública del sujeto para que a su recepción sólo el sujeto que posee la clave privada pueda leerlo. Entonces para firmar un documento digital, su autor utiliza su propia clave secreta (sistema criptográfico asimétrico), a la que sólo él tiene acceso, lo cual impide que pueda después negar su autoría (no revocación).

La Firma en definitiva es un bloque de caracteres que acompaña a un documento acreditando el autor del mismo (autenticación), además de que asegura la integridad del documento evitando cualquier manipulación posterior de los datos. A través de la firma digital el autor queda vinculado al documento de la firma. La validez de la firma digital podrá ser comprobada por cualquier persona que disponga de la clave pública del autor.

El funcionamiento en sí de la firma digital consiste en que el software del firmante aplica un algoritmo hash sobre el texto a firmar, que es un algoritmo matemático unidireccional, de manera que al encriptarse no se puede desencriptar. En el caso de haber un mínimo cambio en el mensaje, trae como consecuencia un extracto completamente diferente al que originalmente firmó el autor. Los algoritmos hash más utilizados son el MD5 ó SHA-1. El extracto conseguido se somete a cifrado mediante la clave secreta del autor. El algoritmo más utilizado en la encriptación asimétrica es el RSA, lo cual da como resultado un extracto final cifrado con la clave privada del autor que se añadirá al final del texto o mensaje para que se pueda verificar la autoría e integridad del documento, por la persona que tenga la clave pública del autor, pudiendo comprobarse que la firma es válida. El software del receptor previa introducción en el mismo de la clave pública del emisor, descifrará el extracto cifrado del autor, calculando el extracto hash que le correspondería al texto del mensaje, y si hay coincidencia con el extracto anteriormente descifrado se consideraría válida, de lo contrario se considera que el documento ha sufrido una modificación posterior y por tanto no sería válido.

Todo este procedimiento se garantiza a través de una autoridad de certificación (CA Certification Authority), certificando e identificando a una persona con una 
determinada clave pública. Lo cual se logra por la emisión de certificados de claves públicas firmando con su clave secreta un documento, que sólo es válido por un período de tiempo determinado, asociándose el nombre de un usuario con su clave pública.

Se podría decir que para las personas naturales se denomina Firma Digital, para el caso de las personas jurídicas se denominará Sello Digital.

La Firma digital tiene en la actualidad una gran importancia porque le da validez legal a un documento digital, porque se convierte en medio de prueba de cualquier contrato realizado por medios electrónicos.

\section{2. Ámbitos de utilización de la firma digital}

Entre otras, se podría utilizar la firma digital para las siguientes actividades:

1) Firmar solicitudes que puedan ser enviadas o recogidas desde Internet.

2) Envío de mensajes con cualquier contenido, y con la seguridad que sólo el receptor del mismo lo podrá leer, evitando que terceras personas puedan tener acceso y poderlo leer, aunque el mensaje sea interceptado.

3) Realización de pagos a través de las cuentas bancarias por medio de internet.

4) Compras por Internet con tarjeta de crédito, con la seguridad que el número de la misma no podrá ser utilizado por terceras personas.

5) Envío de oficios, notificaciones, citaciones, entre otras cosas, por parte de los órganos jurisdiccionales.

\section{Pautas mínimas que debe contemplar la legislación de firma digital}

- La ley debe ser general para permitir su uso en diferentes sectores en que el sistema de firma digital tuviese cabida, como es el caso de la privacidad, seguridad en el comercio electrónico y pruebas judiciales.

- La ley debe equiparar la firma digital a la firma ológrafa.

- Debe determinar los requisitos que deberá contener el sistema usado para firmar digitalmente un documento.

- Debe establecer obligaciones para los usuarios, sobre todo relacionadas al secreto de la clave privada.-

- Control de las autoridades certificantes, tanto en su capacitación técnica como lo referente a los procedimientos que utilicen para el manejo de las claves privadas y públicas. 
- Establecer un marco penal adecuado en lo que respecta a las acciones delictivas relacionadas con el uso de firmas digitales.

\section{Precisión terminológica de los conceptos electrónico y digital}

Electrónica, según la Real Academia Española, es una "Ciencia que estudia dispositivos basados en el movimiento de los electrones libres en el vacío, gases o semiconductores, cuando dichos electrones están sometidos a la acción de los campos electromagnéticos". ${ }^{1}$

Según el Diccionario Técnico y Jurídico del Medio Ambiente, digital es el "tipo de señal cuyo significado inmediato depende de la proximidad de un valor real a unos valores predeterminados, a los cuales se les asigna el valor de dígitos sencillos. El caso más simple consiste en asignar el valor cero a cualquier valor de la señal próximo al valor cero y uno a cualquier valor próximo a otro valor predeterminado (esto es lo que se conoce como sistema binario)". ${ }^{2}$

El contenido del alcance del concepto de digital se opone al contenido del concepto de analógico, porque digital significa algo de naturaleza incremental, mientras que analógico expresa algo que varía de forma continua.

"Consideremos un gran salón con un determinado número de lámparas las cuales se encienden y apagan desde un mismo panel. Pueden existir varios interruptores cada uno de los cuales controla (enciende o apaga) un grupo de luces. Al pulsar los interruptores uno por uno, la habitación se ilumina paulatinamente, alcanzándose la iluminación máxima, cuando están dados todos los interruptores y todas las lámparas encendidas.

También podían haberse controlado todas las lámparas con un simple potenciómetro, que produjese su encendido gradual a medida que se va girando desde la posición de apagado hasta la de encendido.

En el primer caso el aumento de luz se efectúa mediante pasos discretos, mientras que en el segundo es de una manera continua". ${ }^{3}$

La electrónica prestó sus más avanzados componentes a la Informática, para construir el computador u ordenador. De manera que los técnicos electrónicos se dedicaron a la fabricación y mantenimiento de los computadores u ordenadores. La mayoría de los técnicos pensaron que tan sólo se trataba de una aplicación más de la electrónica, lo que no sucedió así, porque la

\footnotetext{
1 REAL ACADEMIA ESPAÑOLA. Diccionario de la Lengua Española. Editorial. Editorial Espasa. España. 2000. Pag. 797.

2 DICCIONARIO TÉCNICO Y JURÍDICO DEL MEDIO AMBIENTE. McGraw hill interamericana de españa. 2000. Pag. 289.

${ }^{3}$ ANGULO, José. Electrónica Digital Moderna. Editorial Paraninfo. Tercera Edición. España. 1996. Pag. 19.
} 
electrónica que dio lo mejor de su tecnología a la informática, fue devorada por ésta, por lo que en la actualidad no se concibe un técnico electrónico que no conozca el proceso de información y sus normas y prestaciones.

En la práctica, se cometen errores que se reflejan en la literatura y en la legislación relacionados al alcance y contenido de los conceptos de electrónico y digital. De allí, que algunos hablen de la firma electrónica y de la firma digital. Conceptualmente no existe entre ambos términos ninguna relación género especie, aunque la firma digital aluda a una forma específica de suscripción documental que se vincula con la criptografía asimétrica, y se utilice firma electrónica de un modo más amplio.

Recibe el nombre de electrónica digital, "los circuitos electrónicos que llevan a cabo las operaciones necesarias para obtener las decisiones lógicas. Son significativamente diferentes a los que se usan, por ejemplo, en los aparatos de radio, televisión y osciloscopios, cuyos circuitos forman parte de la denominada ELECTRÓNICA ANALÓGICA".

La autora Apol-Lonia Martínez Nadal, explica que "una clase particular de firma electrónica que podría ofrecer una mayor seguridad es la de las firmas digitales" 5 . Es decir, que esta jurisconsulto comparte la idea de considerar a la firma digital como integrante de la firma electrónica, en otras palabras la firma electrónica digital. Agrega la mencionada escritora, que "estas firmas digitales son tecnológicamente específicas, pues se crean usando un sistema de criptografía asimétrica o de clave pública (frente a las firmas electrónicas tecnológicamente indefinidas como hemos dicho, por cuanto comprenden cualquier método, incluido, pero no limitado, al de los sistemas de clave pública"6.

El Estudio de la electrónica digital no es muy complicada y no requiere conocimientos previos de electrónica, porque tiene una gran semejanza con los procesos racionales del pensamiento humano. El ser humano expresa sus decisiones mediante el habla, la escritura o actuación; de esa forma las decisiones electrónicas digitales son expresadas por señales eléctricas.

A pesar de que como se indicó anteriormente lo electrónico y digital se encuentran y forman lo electrónico digital, ambos conceptos van por caminos separados. Lo digital es una magnitud que aparece en contraposición con lo analógico, y que se refiere a la forma en que se representa la información. Mientras que lo electrónico se refiere a una tecnología específica, que se utiliza en informática, mas no es la única, porque participa junto a otras como la

\footnotetext{
${ }^{4}$ ANGULO, José. Electrónica Digital Moderna. Editorial Paraninfo. Tercera Edición. España. 1996. Pag. 17.

5 MARTÍNEZ NADAL, Apol-Lonia. Comercio Electrónico, Firma Digital y Autoridades de Certificación. 3ra. Edición. Gráficas Rogar, S.A. España. 2001. Pág. 42.

6 MARTÍNEZ NADAL, Apol-Lonia. Comercio Electrónico, Firma Digital y Autoridades de Certificación. 3ra. Edición. Gráficas Rogar, S.A. España. 2001. Pág. 42.
} 
mecánica, eléctrica, magnética, óptica e inclusive otras menos conocidas como las memorias moleculares.

Utilizar el concepto electrónico para referirse a cualquier situación relacionada con las tecnologías de la información es impreciso, porque cuando se utiliza la expresión digital no se limita con ninguna tecnología específica, sino que es la manera convencional que se ha adoptado para tratar la información, independientemente de la tecnología de turno. Porque si los datos que viajan por redes de fibra óptica (tecnología de luz y no electrónica), se hace representar como 0 y 1, lo que sería digitalmente hablando un sistema binario, entonces no sería preciso denominar a dicha transmisión como una comunicación electrónica, sino digital. Lo digital puede ser introducido en cualquier tecnología, en el caso antes planteado podría ser una firma fibra óptica digital. De lo anterior se puede concluir que para generalizar y no ubicar y limitar a la firma digital en alguna tecnología, es preferible hablar de firma digital, y si se requiere más detalle con el nacimiento de nuevas tecnologías dentro de otras ciencias se podría hablar de firma electrónica digital, firma eléctrica digital, y así sucesivamente.

Lo que sucede es que en la actualidad la informática y la electrónica están sumamente unidas, como se ha hecho referencia con anticipación, entonces en estos momentos la firma digital funciona a través de la electrónica, por lo que la firma digital actual es una firma electrónica digital, lo que no quiere decir que posteriormente surjan nuevas tecnologías que puedan ubicar a esta figura de la firma electrónica digital en otros aspectos.

En este orden de ideas se ha manifestado el legislador venezolano cuando en el artículo 1 del Decreto Ley sobre Mensajes de Datos y Firmas Electrónicas, establece la progresividad de la norma, más sin embargo habla de electrónica, con lo que pareciera que hubiese desconocimiento de los términos electrónico y digital:

"Artículo 1. El presente Decreto-Ley tiene por objeto otorgar y reconocer eficacia y valor jurídico a la Firma Electrónica, al Mensaje de Datos y a toda información inteligible en formato electrónico, independientemente de su soporte material, atribuible a personas naturales 0 jurídicas, públicas 0 privadas, así como regular todo lo relativo a los Proveedores de Servicios de Certificación y los Certificados Electrónicos.

El presente Decreto-Ley será aplicable a los Mensajes de Datos y Firmas Electrónicas independientemente de sus características tecnológicas o de los desarrollos tecnológicos que se produzcan en un futuro. A tal efecto, sus normas serán desarrolladas e interpretadas progresivamente, orientadas a reconocer la validez y eficacia probatoria de los Mensajes de datos y Firmas Electrónicas.

La certificación a que se refiere el presente Decreto-Ley no excluye el cumplimiento de las formalidades de registro público o autenticación que, de conformidad con la ley, requieran determinados actos o negocios jurídicos". (resaltado en negrita del Autor). 
En esta continuidad de ideas, la profesora titular de Derecho Mercantil de la Universitat de Illes Balears, Apol-Lonia Martínez Nadal, explica que "una forma electrónica sería simplemente cualquier método o símbolo basado en medios electrónicos utilizado o adoptado por una parte con la intención actual de vincularse o autenticar un documento, cumpliendo todas o algunas de las funciones características de una firma manuscrita".

Ese amplio concepto de firma electrónica, que además es recogido en el artículo 2, apartado 1, de la directiva comunitaria por la que se establece un marco comunitario para la firma electrónica, y en el artículo 2, específicamente en el apartado a) del Real Decreto-Ley 14/1999, de 17 de septiembre, a través del cual se regula la firma electrónica en el Derecho español, "tendrían cabida técnicas tan simples como un nombre u otro elemento identificativo (p. ej., la firma manual digitalizada) incluido al final de un mensaje electrónico, y de tan escasa seguridad que plantean la cuestión de su valor probatorio a efectos de autenticación, aparte de su nula aportación respecto de la integridad del mensaje (exigencias éstas básicas que debe cumplir un mensaje firmado, sea o no electrónico). Tan es así que incluso podría dudarse de su condición de firma, por su nula o escasa utilidad".

Esta distinción es recogida en los intercambios de ideas y discusiones del grupo de trabajo de comercio electrónico de la UNCITRAL, porque al abordar la posible regulación de las firmas digitales, se resaltó la existencia de conceptos amplios como la firma electrónica, y otros más restringidos como firma digital; y se discutió si se debería de ocupar exclusivamente a estas técnicas de criptografía de clave pública o si se debería también tomar en cuenta otras firmas electrónicas, basadas en técnicas distintas de la criptograma asimétrica, tomando en cuenta las técnicas disponibles o en desarrollo que permitan cumplir las funciones características de las firmas manuscritas en un medio electrónico, y que podrían comprender, por ejemplo, la utilización de códigos o contraseñas, o instrumentos de identificación biométrica. En este sentido, la Secretaría General de la CNUDMI incluye ciertas técnicas basadas en la autenticación a través de un dispositivo biométrico basado en la firma manuscrita; con este dispositivo se firma en forma manual con un lápiz especial, en la pantalla del computador o ordenador, siendo analizada por éste y almacenada como un conjunto de valores numéricos que se podrían agregar a los datos de un mensaje y ser recuperados en la pantalla con la finalidad de que el receptor pueda tener como auténtica la firma. Esto quiere decir, que para el funcionamiento de este sistema se requiere el análisis previo de las firmas manuscritas y su almacenamiento utilizando un dispositivo biométrico. En 1997, la CNUDMI celebró su periodo 30 de sesiones, en Viena del 12 al 30 de mayo, y examinó el informe presentado por el grupo de trabajo antes referido (A/CN.9/437), hizo suyas sus conclusiones y le propuso la preparación de un régimen uniforme en relación a la firma digital y de entidades certificadoras. Se llegó a la conclusión que si bien, se podría concentrar la atención en los asuntos de firma digital, por el predominio de la criptografía de clave pública en el comercio electrónico, no se debe pasar por alto el criterio de neutralidad adoptado en la Ley Modelo de la CNUDMI sobre comercio 
electrónico, en lo que respecta a los diversos medios técnicos disponibles. Es por esto que este régimen uniforme no debe desestimar el recurso a otras técnicas de autenticación. Estos criterios se pueden conseguirán el informe de grupo de trabajo sobre comercio electrónico de la Comisión de las Naciones Unidas para el Derecho Mercantil Internacional, acerca de la labor de su $31^{\circ}$ periodo de sesiones, Nueva Cork, 18 a 28 de febrero de 1997, A/CN.9/437, 12 de marzo de 1997, párrafos 19 al 21; como también en el informe de la Comisión de las Naciones Unidas para el Derecho Mercantil Internacional sobre la labor realizada en su 30 o periodo de sesiones, 12 a 30 de mayo de 1997, A/52/17, Nueva Cork, 1997, párrafos 248 a 250. También se recoge esta distinción en la Comunication Ensuring Security and Trust in Electronic Communication: Towards an European Framework for Digital Signaturas and Encryption, de la Comisión Europea (COM 97-503), que tuvo su principal misión de desarrollar una política europea sobre la materia, y donde se estableció un marco común para las firmas digitales; facilitando la confianza de la utilización de firmas digitales y el deber de ser flexibles para poder admitir los desarrollos tecnológicos.

\section{El marco legislativo penal referente a la firma digital}

Cuando se habla de documento electrónico y firma digital, se hace referencia a nuevas figuras jurídicas que traen consecuencias jurídicas y que por tanto implican una nueva categoría de registro que no está expresamente contemplado en las normas penales actuales.

Una futura reforma en el Código Penal deberá contemplar las siguientes situaciones:

I) Uso de la firma digital perteneciente a otra persona.-

2) Creación de una firma digital atribuyéndola a un nombre falso, como medio comisivo de una posterior estafa.-

3) Alteración de un mensaje conociendo la clave privada del destinatario.-

El marco legislativo que otorgare validez jurídica al documento digital firmado digitalmente, debe penalizar las falsificaciones de las firmas digitales. Por lo cual lo más conveniente es tipificar estos delitos extendiendo el significado de los conceptos de firma, documento, instrumento privado, instrumento público, a la firma digital y al documento electrónico.

\section{Consecuencias características de la utilización de la firma digital}

a) INTEGRIDAD: La utilización de la tecnología de la firma digital con la criptografía asimétrica asegura que la información no ha sido modificada, de manera que el mensaje se puede obtener completo, lo cual constituye un requisito sine quanon para otorgarle plena validez jurídica al documento y 
firma. La firma digital detecta la integridad del mensaje firmado, independientemente del medio de su almacenamiento.

b) INALTERABILIDAD: porque la información no se puede alterar cuando la misma es almacenada. Es importante destacar que la firma digital no impide que la información se altere, sino que detecta si ésta fue alterada o no.

c) PERDURABILIDAD: porque la información perdura en el tiempo, característica del medio de almacenamiento.

\section{Posibilidad de incorporar la tecnología de la firma digital a las comunicaciones a realizarse por los tribunales y entre éstos e inclusive de distinta competencia territorial}

Las comunicaciones que realizan los tribunales hacia otros tribunales que se encuentran fuera de la circunscripción judicial, o hacia aquellos organismos públicos ubicados en otros Estados, podrían ser agilizadas mediante el uso de la informática.

Por ejemplo si en Venezuela un juez ordena una prohibición de enajenar y gravar un inmueble ubicado en otro Estado. Previo el cumplimiento de los requisitos de las medidas cautelares, dicho juez podría oficiar directamente al Registro de la propiedad del inmueble enviando la orden de la mencionada prohibición mediante correo electrónico, con el sistema de la firma digital. Lo que traería grandes consecuencias positivas con respecto a la celeridad en el tiempo, y costos y gastos del proceso.

Otro ejemplo similar puede notarse en Argentina mediante la ley 22.172, cuando se requieren medidas a un juez o se ordenan notificar medidas a organismos de otros Estados, como un registro de la propiedad inmobiliaria, de automotor o de registro público de comercio, etc., donde las comunicaciones tienen una gran importancia en lo que se refiere a la eficacia de medidas cautelares. Estas medidas en muchos casos deben ser efectuadas con celeridad para evitar que se tornen ilusorios los derechos de los peticionantes. "Los trámites relativos al uso de esta ley serían agilizados notablemente si se estableciera entre los tribunales oficiantes y los tribunales $u$ organismos receptores la tecnología de la firma digital. Esta tecnología está siendo probada a nivel nacional, mediante la instrumentación de lo dispuesto por el decreto nacional № 427, del 16/4/98, que autoriza por el plazo de dos años, el empleo de la firma digital en la instrumentación de los actos internos del Sector Público Nacional, que no produzcan efectos jurídicos individuales en forma directa. Este sistema permitiría que el juez que ordena una medida cautelar, efectivice la traba de esa medida en extraña jurisdicción, en minutos de haberla dictado."7

Para lograr este cometido se necesita capacitar a todos los tribunales de computadoras aptas para el desarrollo de actividades con firma digital, como

\footnotetext{
7 ARCE, Alfonso, y DÍAZ, Federico. La Firma Digital. Aspectos Jurídicos. Su Aplicación a las Comunicaciones Previstas por la Ley 22.172.
} 
también a los organismos públicos para el mejor cumplimiento de esas funciones.

El sistema de la firma digital es reconocida como alternativa para la desburocratización de la justicia y para la agilización de muchos trámites.

En este sentido el Decreto Ley sobre Mensajes de Datos y Firmas Electrónicas de Venezuela determina en su artículo 3 que "El Estado adoptará las medidas que fueren necesarias para que los organismos públicos puedan desarrollar sus funciones, utilizando los mecanismos descritos en este Decreto-Ley".

\section{Notificación por correo electrónico en Venezuela}

Por sentencia de la Sala Constitucional del Tribunal Supremo de Justicia de la República Bolivariana de Venezuela, de fecha 1 de febrero de 2000, con relación a los recursos de amparo constitucional en cuanto a la citación y notificación, estableció lo siguiente:

"Los Tribunales o la Sala Constitucional que conozcan de la solicitud de amparo, por aplicación de los artículos de la Ley Orgánica de Amparo sobre Derechos y Garantías Constitucionales, admitirán o no el amparo, ordenarán que se amplíen los hechos y las pruebas, o se corrijan los defectos u omisiones de la solicitud, para lo cual se señalará un lapso, también preclusivo. Todo ello conforme a los artículos 17 y 19 de la Ley Orgánica de Amparo sobre Derechos y Garantías Constitucionales.

Admitida la acción, se ordenará la citación del presunto agraviante y la notificación del Ministerio Público, para que concurran al tribunal a conocer el día en que se celebrará la audiencia oral, la cual tendrá lugar, tanto en su fijación como para su práctica, dentro de las noventa y seis (96) horas a partir de la última notificación efectuada. Para dar cumplimiento a la brevedad y falta de formalidad, la notificación podrá ser practicada mediante boleta, 0 comunicación telefónica, fax, telegrama, correo electrónico, o cualquier medio de comunicación interpersonal, bien por el órgano jurisdiccional o bien por el Alguacil del mismo, indicándose en la notificación la fecha de comparecencia del presunto agraviante y dejando el Secretario del órgano jurisdiccional, en autos, constancia de haberse efectuado la citación o notificación y de sus consecuencias" (Sentencia de fecha 01-02-2000).

En este sentido, considera el autor de esta investigación que la notificación por correo electrónico planteada en la anterior sentencia de la Sala Constitucional del Tribunal Supremo de Justicia, crea inseguridad jurídica y podría llegar a violar el derecho de defensa de las personas. Porque para utilizar el correo electrónico como mecanismo de citación o notificación en la función jurisdiccional, son necesarios sistemas de seguridad que acrediten fiabilidad de la información contenida en la citación o notificación electrónica.

Para el ejercicio de una efectiva notificación electrónica se necesitaría la tecnología de la firma digital, con la que se asegura el contenido del mensaje- 
notificación, evitando que terceras personas lo intercepten, pero además, sería necesario un programa por medio del cual el emisor del mensaje, que en este caso sería el tribunal emisor de la notificación, pueda saber en que momento el correo fue abierto y por lo tanto leído, porque sería esa constancia la que se debe consignar en el expediente para determinar la validez de la notificación electrónica.

Con respecto a la notificación por correo electrónico, explicó Velarde (2001), en el I Congreso Andino de Derecho e Informática celebrado los días 28, 29 y 30 de marzo de 2001, en Maracaibo, Venezuela, que el 6 de febrero del 2001, se promulgó en el Perú la Ley № 27419, Ley sobre Notificación por Correo Electrónico, mediante la cual se autoriza a las autoridades judiciales a remitir las resoluciones emitidas dentro de un proceso judicial, por medio del correo electrónico.

Sin embargo, la mencionada jurisconsulta explicó que la mencionada Ley establece requisitos para garantizar el valor de la notificación electrónica:

“- Confirmación de recepción: El correo electrónico podrá ser utilizado siempre y cuando permita confirmar la recepción del mismo. Este requisito implica la actualización tecnológica del Poder Judicial y de los usuarios, ya que los programas de correos utilizados deberán estar en capacidad de emitir un recibo de entrega, apertura y estado del correo.

- Sólo se notificará por correo electrónico a la parte que lo hubiere solicitado: Esta premisa acepta, por tanto, el envío de documentos del juzgado hacia la parte más no de la parte hacia el juzgado.

- Los gastos quedan incluidos en la condena de costas: Sin embargo, a nuestro parecer, los gastos en que incurra una parte o el propio juzgado por haber instalado un programa de correo electrónico, o haberlo adquirido, o el pago de la línea telefónica por conectarse a Internet, deben ser asumidos por la parte que solicitó recibir las notificaciones a través del correo electrónico. Asimismo, el Poder Judicial debe, mediante su presupuesto público, equipar a los juzgados con al adecuada tecnología para cumplir con la ley de Notificación por Correo Electrónico.

- Se dejará constancia en el expediente del ejemplar de la notificación entregado para su envío. Así también, se anexará al expediente el reporte técnico: La acumulación de fojas a que conllevan estos requisitos no permiten considerar la posibilidad de contar posteriormente con un expediente, ya que aún se otorga mayor valor probatorio al documento en soporte papel.

- La Notificación por correo electrónico contendrá los mismos datos que la cédula de notificación judicial (notificación tradicional): La notificación electrónica deberá ajustarse a las pautas establecidas en el Código Procesal Civil Peruano". 


\section{Conclusiones}

- El Derecho Informático constituye una rama autónoma del Derecho, por tener sus principios, instituciones propias, legislación, doctrina, figuras jurídicas propias, cuyos estudios se constituyen en la doctrina, Jurisprudencia especial, y que ha dado como consecuencia la cátedra de Derecho Informático tanto a nivel de pregrado como de postgrado, y naciendo así centros e instituciones de investigación de la interrelación entre el Derecho y la Informática.

- También, el mencionado Decreto Ley brinda seguridad jurídica a las relaciones comerciales y a las inversiones tanto nacionales como extranjeras, y juega un papel fundamental en la privacidad de los usuarios, así como el control por parte del Estado.

- La citación y notificación por correo electrónico planteada en sentencia de la Sala Constitucional del Tribunal Supremo de Justicia de la República Bolivariana de Venezuela, puede crear inseguridad jurídica y podría llegar a violar el derecho de defensa de las personas. Porque para utilizar el correo electrónico como mecanismo de citación o notificación en la función jurisdiccional, son necesarios sistemas de seguridad que acrediten fiabilidad de la información contenida en la notificación electrónica.

- $\quad$ La firma digital tiene en la actualidad una gran importancia; le da validez legal a un documento electrónico digital, y porque es un medio de prueba de cualquier contrato realizado por medios electrónicos.

- $\quad$ El Decreto Ley sobre Mensajes de Datos y Firmas Electrónicas tiene por objeto reconocer eficacia y valor jurídico a la Firma Electrónica, al Mensaje de Datos y a toda información inteligible en formato electrónico, independientemente de su soporte material, atribuible a personas naturales o jurídicas, públicas o privadas, así como regular todo lo relativo a los Proveedores de Servicios de Certificación y a los Certificados Electrónicos. Homologa los efectos de la firma autógrafa a la firma electrónica, establece los requisitos mínimos que confieran seguridad e integridad a los mensajes de datos y a la firma electrónica, establece los requisitos mínimos que debe tener un Certificado Electrónico, crea un Registro de Proveedores de Servicios de Certificación, crea la Superintendencia de Servicios de Certificación Electrónica para registrar y supervisar a los Proveedores de Servicios de Certificación. Con estos elementos principales y otros que se establecen en este proyecto de ley, se brinda seguridad y certeza jurídica a los actos y negocios electrónicos, mientras se perfeccionan y estandarizan los usos, costumbres y modos de relacionarse y comerciar por este medio a nivel mundial.

\section{Recomendaciones}

- $\quad$ Es necesario el desarrollo, estudio y aplicación del derecho informático y la informática jurídica, como ciencias autónomas que tienen su marco strictu en la iuscibernética, para dar solución a los problemas que surgen de la aplicación de las altas tecnologías informáticas. 
El Derecho Informático y la Informática Jurídica por constituirse en un conjunto de conocimientos determinados relacionados al campo jurídico, que les diferencian de otras ciencias, deben ser considerados como temas importantes en la formación integral del abogado y de los jueces.

- Deben desarrollarse normas legales, que regulen la aplicación de la informática, para su desarrollo idóneo y con respeto a los derechos fundamentales del hombre, como el derecho a la privacidad, intimidad, sancionando leyes referidas al hábeas data, ya sea que se intente vía administrativa o jurisdiccional.

- $\quad$ Se aspira que se comience en Venezuela a tomar en cuenta tanto a nivel institucional como académico el derecho informático y su importancia en la sociedad actual, la cual se desarrolla y se desenvuelve cada vez más, a través de los novedosos medios informáticos y telemáticos.

\section{Bibliografía}

\section{Material Doctrinario :}

ARY, Donald y otros. Introducción a la Investigación. Editorial Mc Graw-Hill. México. 1.987. Pág. 395.

BREWER, Allan y otros. Leyes para la Descentralización Política de la Federación. Editorial Jurídica Venezolana. Caracas. 1.990. Pág.299.

CABANELLAS DE TORRES, Guillermo. Diccionario Jurídico Elemental.

COUTURE, Eduardo. Fundamentos del Derecho Procesal Civil. Tercera Edición.

CUENCA, Humberto. Derecho Procesal Civil.

DÍAZ SIEIRO, Horacio; VELJANOVICH, Rodolfo; BERGROTH, Leonardo. Procedimiento Tributario. Ediciones Macchi. Buenos Aires. 1.993. Pág. 841.

DUGUIT LEÓN. Traité de Droit Constitutionnel. Tomo II.

FRIEDMAN, Lawrence. American Law. An Introduction. Norton \& Company. U.S.A. 1.984. Pág. 362.

INSTITUTO DE ESTUDIOS JURÍDICOS DEL ESTADO LARA. II Jornadas sobre Derecho y Computación. Vadell Hermanos Editores. CumanáVenezuela. 1.992. Pág. 210.

Material entregado en guía de las XV Jornadas Iberoamericanas de Derecho Procesal. 
PEÑARANDA QUINTERO, Héctor Ramón. Iuscibernética: Interrelación entre el Derecho y la Informática. Fondo Editorial para el Desarrollo de la Educación Superior (FEDES). Caracas. 2001. Pág. 293.

El Principio de Legalidad en Materia Tributaria. Informe. Presentado en la Maestría en Gerencia Tributaria de la Universidad Rafael Belloso Chacín. Maracaibo. Julio. 1.996. Pág. 14.

, La Relación Derecho - Informática como Asignatura para Juristas e Informáticos. VI Congreso Iberoamericano de Derecho e Informática. Libro de Ponencias. Uruguay. 1.998. Pág. 998.

SABINO, Carlos. El Proceso de Investigación. El Cid Editor. Argentina. 1.975. Pág. 480.

SÁNCHEZ ARANGUREN, Basilio y GUARISMA, José. Métodos de Investigación. Ediciones Universidad Bicentenaria de Aragua. Caracas. 1.985. Pág.210.

SERRANO, Alberto. Computadoras y Derecho.Colecciones de Monografías del CEFD-LUZ. Maracaibo-Venezuela. 1.975. Pág. 128.

THE WORKING GROUP OF THE DOMESTIC COUNCIL. The Status of Federalism in America. Report. U.S.A. 1.986.

Leyes :

CONGRESO NACIONAL. Código Civil Venezolano.

CONGReso NACIONAL. Código de Procedimiento Civil de Venezuela.

CONGRESO NACIONAL DE LA REPÚBLICA DE VENEZUELA. Ley Orgánica de Procedimientos Administrativos. Gaceta Oficial No. 2.818. Extraordinario del 10. de Julio de 1.981.

DECRETO LEY SOBRE MENSAJES DE DATOS Y FIRMAS ELECTRÓNICAS DE VENEZUELA

CONSTITUCIÓN NACIONAL DE LA REPÚBLICA BOLIVARIANA DE VENEZUELA

Diccionarios y/o Enciclopedias :

DICCIONARIO JURÍDICO VENEZOLANO D\&F. IV Tomos. Líder Editores. Caracas.

ENCICLOPEDIA JURÍDICA OMEBA. Tomos XXVI. Bibliográfica Omeba. Buenos Aires. 1.974. Pág. 1.165. 